\title{
Sugar Sweetened Beverages Attributable Disease Burden and the Potential Impact of Policy Interventions: A Systematic Review of Epidemiological and Decision Models
}

\section{Andrea Alcaraz ( $\nabla$ aalcaraz@iecs.org.ar)}

Instituto de Efectividad Clínica y Sanitaria (IECS) /Institute for Clinical Effectiveness and Health Policy Andres Pichon-Riviere

Instituto de Efectividad Clínica y Sanitaria (IECS) /Institute for Clinical Effectiveness and Health Policy

Alfredo Palacios

Instituto de Efectividad Clínica y Sanitaria (IECS) /Institute for Clinical Effectiveness and Health Policy

Ariel Bardach

Consejo Nacional de Investigaciones Científicas y Técnicas (CONICET)

Dario Balan

Instituto de Efectividad Clínica y Sanitaria (IECS) /Institute for Clinical Effectiveness and Health Policy

Lucas Perelli

Instituto de Efectividad Clínica y Sanitaria (IECS) /Institute for Clinical Effectiveness and Health Policy

Federico Augustovski

Instituto de Efectividad Clínica y Sanitaria (IECS) /Institute for Clinical Effectiveness and Health Policy

Agustín Ciapponi

Instituto de Efectividad Clínica y Sanitaria (IECS) /Institute for Clinical Effectiveness and Health Policy

\section{Research Article}

Keywords: Sugar sweetened beverages (SSBs), Burden of disease, Economic evaluations, Decision Models, Epidemiological Models, Health policies

Posted Date: January 15th, 2021

DOl: https://doi.org/10.21203/rs.3.rs-143826/v1

License: (9) (1) This work is licensed under a Creative Commons Attribution 4.0 International License. Read Full License 
Version of Record: A version of this preprint was published at BMC Public Health on July 27th, 2021. See the published version at https://doi.org/10.1186/s12889-021-11046-7. 


\section{Abstract}

Background Around 184000 deaths per year could be attributable to sugar sweetened beverages (SSBs) consumption worldwide. Epidemiological and decision models are important tools to estimate disease burden. The purpose of this study was to identify models to assess the burden of diseases attributable to SSBs consumption or the potential impact of health interventions.

Methods We carried out a systematic review and literature search up to August 2018. Pairs of reviewers independently selected, extracted, and assessed the quality of the included studies through an exhaustive description of each model features. Discrepancies were solved by consensus. The inclusion criteria were epidemiological or decision models evaluating SSBs health interventions or policies, and descriptive SSBs studies of decision models. We excluded studies published before 2003, cost of illness studies and economic evaluations based on individual patient data.

Results We identified a total of 2766 references. Out of the 40 included studies, $45 \%$ were models specifically developed to address SSBs, $82.5 \%$ were conducted in high income countries and $57.5 \%$ considered a health system perspective. The most common model's outcomes were obesity/overweight $(82.5 \%)$, diabetes $(72.5 \%)$, cardiovascular disease (60\%), mortality $(52.5 \%)$, direct medical costs $(57.35 \%)$, and healthy years -DALYs/QALYs- $(40 \%)$ attributable to SSBs. $67.5 \%$ of the studies modelled the effect of SSBs on the outcomes either wholly through BMI or through BMI plus diabetes independently. Models were usually populated with inputs from national surveys -like obesity prevalence, SSBs consumption-; and vital statistics $(67.5 \%)$.

Only $55 \%$ reported results by gender and $40 \%$ included children; $30 \%$ presented results by income level, and $25 \%$ in selected vulnerable groups. Most of the models evaluated at least one policy intervention to reduce SSBs consumption (92.5\%), being taxes the most frequent $(75 \%)$.

Conclusions There is a wide range modelling approaches with different complexity and information requirements to evaluate the burden of disease attributable to SSB. The majority consider the impact on obesity, diabetes and cardiovascular disease, mortality, and economic impact. Incorporating these tools to different countries could generate useful information for decision makers and the general population to promote the deeper implementation of policies to diminish SSB consumption.

\section{Background}

Worldwide, non-communicable diseases (NCD) were responsible for more than $50 \%$ of global health burden in 2013, accounting for 38.3 million deaths [1]. About $80 \%$ of these premature NCD deaths occur in low- and middle-income countries (LMICs) [2]. Additionally, these non-communicable diseases have a huge attributable cost on health systems as well as to the society as a whole [3-8]. This enormous disease burden represents a major barrier to the achievement of the Millennium Development Goals. [2]. 
Obesity is an important determinant of the burden of disease currently attributable to NCDs. In 2015, nearly 110 million children and more than 600 million adults were obese. Since 1980, the prevalence of obesity has doubled in more than 70 countries and has continuously increased in most other countries [9]. The proportion of overweight or obesity adults increased between 1980 and 2013 from $28.8-36.9 \%$ in men, and from $29.8-38.0 \%$ in women [10]. Obesity-attributable diseases cause more than 17 million global deaths each year $[11,12]$. The rates of childhood overweight and obesity have increased across all age and socioeconomic status (SES) groups. These trends have been remarkable in highly urbanized areas. Obese children are at increased risk of type 2 diabetes, high blood pressure, asthma, sleep disorders, liver disease, low self-esteem, depression and social isolation, and obese adults are more prone to cardiovascular diseases (CVD) and obesity-related cancers. Obesity is a multi-causal phenomenon, that includes unhealthy dietary patterns and sedentarism, among others. Dietary surveys indicate that foods and beverages high in free sugars can constitute a major source of discretionary calories: added sugars supply food energy but no other nutrients (also called "empty calories").

Sugar sweetened beverages (SSB) consumption has been linked to an increased risk for type 2 diabetes, obesity [13-15], obesity-related cancers[16], hypertension[17], coronary heart disease[15], and tooth decay [18-23]. Dental burden can also represent 5-10\% of health-care budgets in industrialized countries, and even more so in low-income countries [24, 25].

Worldwide, it has been estimated that 184000 deaths per year could be attributable to SSBs consumption: 133000 from diabetes mellitus, 45000 from CVD, and 6450 from cancers. [26]. SSB consumption varies considerably by geographic location, gender, age and socio-economic status. World adults mean daily SSB consumption was estimated at $137 \mathrm{~mL}(95 \% \mathrm{Cl}: 88$ to $211 \mathrm{~mL}$ ) in 2010 and is usually higher in persons in younger age, low-income groups and among males [26]. with large disparities between countries. These beverages include soft drinks, sodas, fruit drinks, sweetened coffees and teas, energy drinks, sports drinks, and sweetened waters. SSB constitutes the single largest source of added sugars in the American diet, and over $5 \%$ of overall caloric intake $[27,28]$. Although full-calorie beverage consumption is declining, beverage consumption as a whole is increasing, especially with the mid-calorie drinks (e.g., sports drinks, teas, and energy drinks) [29].

Although many countries around the world are considering, or have begun to implement, a series of measures aimed at tackling SSB consumption, there is also a lack of awareness from decision-makers, stakeholders and the general population on this topic and also many interventions generate resistance (such as increasing taxes). There are interventions of a wide range of spectrum that involves decision makers and key leaders of disparate sectors; these include fiscal policies that tax SSB, front of package regulation, educational measures, modification of the school environment, ban of publicity, promotion and sponsorship, among other interventions. [30-34]. To have information on the burden of disease like impact on health and economics of SSB consumption as well as cost-effectiveness and expected impact of implementing public health policies could facilitate to move forward.[22] Assessments based on epidemiological and decision models are widely accepted as decision-making tools and can provide valuable information for optimizing the allocation of health resources. [35] 
This study is part of a larger multi-country study funded by the International Development Research Centre (IDRC) and oriented to empowering healthcare decision makers to achieve regional needs in SSB policies in Latin America and the Caribbean through the evaluation of disease and economic burden and the cost-effectiveness of available interventions.

The purpose of this study was to identify epidemiological or decision models to assess the burden of disease attributable to SSB consumption or the cost-effectiveness of interventions aimed to reduce SSB consumption, through a systematic review.

\section{Methods}

A systematic review of the published literature was carried out according to the parameters for reporting proposed in the guidelines for Meta-analysis Of Observational Studies in Epidemiology (MOOSE) [36] and Preferred reporting items for systematic reviews and meta-analyses (PRISMA) )[37].

We undertook a systematic search up to August 2018 in the following biomedical bibliographic databases: MEDLINE (Ovid), Cochrane (Wiley), EMBase (Elsevier), CINAHL (EBSCO), LILACS (iAH). Details about the electronic searches carried out are provided in the Additional file 1, 1. We also hand-searched reference-lists of published systematic reviews (SR) of models for additional information and performed a prospective citation tracking.

\section{Selection process, eligibility and risk of bias (quality) assessment}

Pairs of reviewers independently selected articles initially by title and abstract and subsequently by evaluating the full texts of studies meeting the inclusion criteria, using the software Covidence [38, 39]. For the eligibility of articles, the following criteria were established: 1) epidemiological or decision models that explore SSB related disease burden reporting attributable deaths and at least one of the following outcomes: Disability-Adjusted Life Years (DALYs), Quality-Adjusted Life Years (QALYs), or Years of Life Lost (YLLs), 2) model-based economic evaluations of health interventions or policies, implemented or implementable at the city, state, or national level, and 3) descriptive studies of decision models that explore disease burden or cost-effectiveness. The exclusion criteria were: 1) publishing date before the year 2003, 2) cost-only studies, 3) model not specific about SSB or which does notshow effects separately for SSBs, 4) economic evaluations based only on randomized controlled trials (piggyback studies). Using Brennan et al. paper [40] we defined a model as a formal quantified comparison, synthesizing sources of evidence on costs and benefits, in order to identify the best option for decision makers to adopt. This author additionally proposed a model taxonomy according to different dimensions. We simplified this taxonomy to relieve whether the models incorporated interactions between the individuals; were epidemiological or aggregated level; if they were "timed" and explicitly incorporated a time (usually in cycle lengths); or were based on cohorts or individual level. 
Pairs of reviewers independently extracted data using a previously piloted data extraction form and assessed the risk of bias (quality) of the included studies. In case of disagreements, it was resolved by consensus. In case of difficulty to reach a consensus, a third author made the final decision. Considering the nature of our research question, a specific risk of bias (quality) assessment tool was not judged to be applicable. Nevertheless, we used the items of the data extraction template to assess the exhaustiveness of the model features and description.

\section{Data synthesis}

We performed a descriptive synthesis of the main characteristics of the identified models.

For each model we considered type of model, frequency of use in public health, specificity for SSBs attributable effects, time horizon, perspective, age, sex, SES and countries of application. We assessed the following features: presence of interaction between individuals, degree of information aggregation (individual, aggregate, econometric or epidemiological), temporal dimension incorporation, and number of cohorts that require (one cohort vs multicohort). Regarding model's inputs, we specified if the models require incidence data by condition, vital data, longitudinal data, representative surveys or other data.

For outcomes, we analyzed if they reported: variations in the degree of consumption, obesity/overweight, diabetes, mortality, cardiovascular disease, cancer, teeth cavities, bullying, other health outcomes; DALYs, QALYs or YLL; direct or indirect costs; tax revenue, sales of sugary drinks and health equity aspects. For cost-effectiveness models we also considered which type of intervention was being evaluated: taxation, school environment modifications, advertising, labeling or others. We estimated the workload needed to complete populating the model according their type and also the applicability to the Latin-American and Caribbean context. In both cases they scored as low, medium or high effort /applicability and the final decision was reached by group consensus.

For each model we finally identified its underlying disease causal pathway and graphically summarized these by grouping the models that used a similar pathway and / or that reported results in the same way.

\section{Results}

We identified a total of 2766 references from the bibliographic databases (2709 after remove duplicates). Of them, we selected 87 for eligibility by full-text screening and we finally included 40 studies[25, 27, 4077] published between 2012 and 2018 (See Fig. 1. The study flow diagram).

The descriptive statistics of the included SSB model characteristics are described in Table 1 and Table 2. A detailed description of each model features, taxonomy, inputs, results, subgroups analyzed, interventions evaluated, and applicability can be found in Additional file 2 to 7.

Out of the 40 included studies only $45 \%$ were exclusive for SSBs, while in the rest of the models SSBs was one of the risk factors evaluated by the model along with others (e.g. obesity or cardiovascular risk factors). $72.5 \%$ analyzed a maximum time horizon of 10 or more years; only $25 \%$ considered child 
population separately. Only $12.5 \%$ included a Latin-American country while $82.5 \%$ were conducted in high income countries, majority in USA, Australia and UK. Most of the models had a health system perspective (57.5\%).

Regarding the model taxonomy, none incorporated interactions between the individuals; most were classified as epidemiological (42.5\%), aggregated -non individual- level (35.5\%), timed (50\%), and based on cohort (62.5\%).

Majority of models involve moderate applicability effort or requirements $(85 \%)$ and show moderate applicability to Latin-America and Caribbean region (87.5\%).

Most models required inputs from national surveys -like obesity prevalence, SSB consumption-; vital statistics $(67.5 \%)$ mainly related to specific disease mortality; and countries' disease incidence (52.5\%). See Table 1. 
Table 1

Descriptive statistics of the included SSBs models: features, taxonomy and applicability.

\begin{tabular}{|c|c|c|c|}
\hline Model & Descriptive variables & $\begin{array}{l}\text { Frequency ( } \mathrm{N}=40 \\
\text { studies) }\end{array}$ & $\%$ \\
\hline \multirow[t]{14}{*}{ Features } & Sugar-specific & $N=18$ & $45.0 \%$ \\
\hline & \multirow[t]{4}{*}{ Time horizon (maximum) } & 1 year $=8$ & $22.5 \%$ \\
\hline & & $2-10$ years $=14$ & $35.0 \%$ \\
\hline & & $11-25$ years $=9$ & $22.5 \%$ \\
\hline & & Lifetime $=8$ & $20.0 \%$ \\
\hline & \multirow[t]{3}{*}{ Population } & Adults only $=21$ & $52.5 \%$ \\
\hline & & Childs only = 2 & $5.0 \%$ \\
\hline & & Total population $=17$ & $42.5 \%$ \\
\hline & \multirow[t]{3}{*}{ Country by income } & High $I C=30$ & $75,00 \%$ \\
\hline & & Low and middle $\mathrm{IC}=9$ & $22,50 \%$ \\
\hline & & Worldwide $=1$ & $2,50 \%$ \\
\hline & \multirow[t]{3}{*}{ Perspective } & Government $=6$ & $15.0 \%$ \\
\hline & & Health system $=23$ & $57.5 \%$ \\
\hline & & Societal = 11 & $27.5 \%$ \\
\hline \multirow[t]{10}{*}{ Taxonomy } & Interaction allowed & $N=0$ & $0 \%$ \\
\hline & \multirow{4}{*}{$\begin{array}{l}\text { Aggregate/ Individual/ econometric/ } \\
\text { epidemiological }\end{array}$} & Aggregate $=14$ & $35.0 \%$ \\
\hline & & Individual = 1 & $2.5 \%$ \\
\hline & & Econometric $=8$ & $20.0 \%$ \\
\hline & & Epidemiological = 17 & $42.5 \%$ \\
\hline & \multirow[t]{3}{*}{ Time incorporation } & Timed $=20$ & $50.0 \%$ \\
\hline & & Untimed $=13$ & $32.5 \%$ \\
\hline & & Continuous $=6$ & $15.0 \%$ \\
\hline & \multirow[t]{2}{*}{ Cohort } & Cohort $=25$ & $62.5 \%$ \\
\hline & & Multi-cohort = 8 & $20.0 \%$ \\
\hline \multirow[t]{2}{*}{ Applicability } & \multirow[t]{2}{*}{ Effort / requirements } & Low $=4$ & $10.0 \%$ \\
\hline & & Moderate $=34$ & $85.0 \%$ \\
\hline
\end{tabular}




\begin{tabular}{|llll|}
\hline Model & Descriptive variables & $\begin{array}{l}\text { Frequency }(\mathbf{N}=\mathbf{4 0} \\
\text { studies })\end{array}$ & $\%$ \\
\hline Applicability / reproducibility & High $=2$ & $5.0 \%$ \\
\hline & Moderate $=35$ & $87.5 \%$ \\
\cline { 2 - 3 } & High $=5$ & $12.5 \%$ \\
\hline
\end{tabular}

The most common results provided by the burden of disease models were obesity/overweight (82.5\%), diabetes (72.5\%), cardiovascular disease (60\%), mortality (52.5\%), direct medical costs $(57.35 \%)$, and DALYS/QALYs (40\%) attributable to SSBs. Only two models incorporate diseases not related with obesity such cavities. Equity analysis was considered in one third of the studies. Models that evaluated the impact of interventions also included the variation in SSBs consumption (85\%) but only $17.5 \%$ reported tax collection or SSB sales.

Regarding the analysis of different population subgroups, $55 \%$ reported results by gender and $40 \%$ included children; just $30 \%$ of the models presented results by income level, and only $25 \%$ by vulnerable groups.

Most of models evaluated at least one intervention (92.5\%), being taxes the most evaluated intervention (75\%) followed by school environments (12.5\%) and advertising (10\%). See Table 2. 
Table 2

Descriptive statistics of the included SSBs models: inputs, results, subgroups and interventions.

\begin{tabular}{|c|c|c|c|}
\hline Model & Descriptive variables & Frequency ( $\mathrm{N}=40$ studies) & $\%$ \\
\hline \multirow[t]{5}{*}{ Inputs } & Incidence & $N=21$ & $52.5 \%$ \\
\hline & Vital statistics & $N=27$ & $67.5 \%$ \\
\hline & Longitudinal data & $N=9$ & $22.5 \%$ \\
\hline & Population survey & $N=37$ & $87.5 \%$ \\
\hline & Elasticity/consumption & $N=15$ & $37.5 \%$ \\
\hline \multirow[t]{18}{*}{ Results } & Obesity/Overweight & $N=36$ & $90.0 \%$ \\
\hline & Diabetes & $N=29$ & $72.5 \%$ \\
\hline & Cardiovascular disease & $N=31$ & $77.5 \%$ \\
\hline & Cancer & $N=13$ & $32.5 \%$ \\
\hline & Cavities & $N=2$ & $5.0 \%$ \\
\hline & Osteoarthritis & $N=2$ & $5.0 \%$ \\
\hline & Incidence & $N=3$ & $7.5 \%$ \\
\hline & Prevalence & $N=6$ & $15.0 \%$ \\
\hline & Mortality & $N=21$ & $52.5 \%$ \\
\hline & Life years & $N=11$ & $27.5 \%$ \\
\hline & DALYs/QALYs & $N=16$ & $40.0 \%$ \\
\hline & Direct costs & $N=23$ & $57.5 \%$ \\
\hline & Indirect costs & $N=6$ & $15.0 \%$ \\
\hline & Cost-effectiveness & $N=7$ & $17.5 \%$ \\
\hline & Variation in consumption & $N=34$ & $85.0 \%$ \\
\hline & SSB sales & $N=7$ & $17.5 \%$ \\
\hline & Tax collection & $N=7$ & $17.5 \%$ \\
\hline & Equity & $N=13$ & $32.5 \%$ \\
\hline \multirow[t]{3}{*}{ Subgroups } & Children/teenage & $N=16$ & $40.0 \%$ \\
\hline & Gender & $N=22$ & $55.0 \%$ \\
\hline & Income level & $N=12$ & $30.0 \%$ \\
\hline
\end{tabular}




\begin{tabular}{|llll|}
\hline Model & Descriptive variables & Frequency $(\mathbf{N}=\mathbf{4 0}$ studies) & $\%$ \\
\hline \multirow{2}{*}{ Interventions evaluated } & Vulnerable groups & $\mathrm{N}=10$ & $25.0 \%$ \\
& Taxes & $\mathrm{N}=30$ & $75.0 \%$ \\
\cline { 2 - 4 } & School environment & $\mathrm{N}=5$ & $12.5 \%$ \\
\cline { 2 - 3 } & Advertising & $\mathrm{N}=4$ & $10.0 \%$ \\
& Labelling & $\mathrm{N}=2$ & $5.0 \%$ \\
& Subsidies & $\mathrm{N}=2$ & $5.0 \%$ \\
\hline
\end{tabular}

After analyzing each model causal (structural) pathway, we grouped them in six main pathway patterns, which are graphically presented in Fig. 2 Models' pathways groups; complemented by data in Table 3 . The most frequent pathway (35\%) included the effects of SSB intake on BMI with the mortality and quality of life of the obesity plus the effects of diabetes and other related diseases/conditions including mortality, DALYS/QALYs and cost associated with treating them. A similar pathway that was almost as frequent $(32.5 \%)$ does not consider diabetes independently, but it was included with all the other conditions (mainly cardiovascular disease and cancer) (see Fig. 2, groups 2 and 3). Models that used the simplest pathway that only include SSB intake to BMI represent $17.55 \%$ of the cases. The other pathways were less frequent or not used at all. We present each model pathway graphically in figures in Additional file 8. 
Table 3

Disease pathway pattern groups of the included SSB models.

\begin{tabular}{|c|c|c|c|c|}
\hline \multicolumn{2}{|c|}{ Pathway pattern } & \multirow{2}{*}{$\begin{array}{l}\mathbf{N}(\%) \\
7 \\
(17.5 \%)\end{array}$} & \multirow{2}{*}{$\begin{array}{l}\text { Studies ID } \\
\text { Briggs 2013a, Briggs 2013b, Kristensen 2014, } \\
\text { Lee 2018, Manyema 2014, Vecino-Ortiz 2018, } \\
\text { Wilson 2015. }\end{array}$} & \multirow{2}{*}{$\begin{array}{l}\text { References } \\
{[25,46,47,} \\
55,57,63, \\
76]\end{array}$} \\
\hline Group & Only BMI & & & \\
\hline $\begin{array}{l}\text { Group } \\
2\end{array}$ & $\begin{array}{l}\text { BMI + BMI- } \\
\text { related } \\
\text { conditions / } \\
\text { consequences }\end{array}$ & $\begin{array}{l}13 \\
(32.5 \%)\end{array}$ & $\begin{array}{l}\text { Collins 2015, Gortmaker 2015b, Gortmaker } \\
2015 a \text {, Lin 2011, Long 2015, Manyema 2015, } \\
\text { Manyema 2016, Nomaguchi 2017, Pearson- } \\
\text { Stuttard 2017, Rezende 2016, Sacks 2011, Singh } \\
\text { 2015, Wright } 2015\end{array}$ & $\begin{array}{l}{[27,51,53} \\
54,59,61 \\
62,66,67 \\
69,70,73 \\
77]\end{array}$ \\
\hline $\begin{array}{l}\text { Grupo } \\
3\end{array}$ & $\begin{array}{l}\text { BMI + BMI- } \\
\text { related } \\
\text { conditions + } \\
\text { Diabetes }\end{array}$ & $\begin{array}{l}14 \\
(35.0 \%)\end{array}$ & $\begin{array}{l}\text { Afshin 2015, Basu 2013, Brown 2018, Breeze } \\
\text { 2017, Briggs 2017, Cobiac 2017, Crino 2017, Lal } \\
\text { 2017, Magnus 2016, Mekonnen 2013, Penalvo } \\
\text { 2017, Sanchez Romero 2016, Veerman 2016, } \\
\text { Wang } 2012\end{array}$ & $\begin{array}{l}{[40,43,45} \\
48-50,52 \\
56,61,65 \\
68,71,74 \\
75]\end{array}$ \\
\hline $\begin{array}{l}\text { Group } \\
4\end{array}$ & $\begin{array}{l}\text { BMI+ } \\
\text { Diabetes }\end{array}$ & $\begin{array}{l}4 \\
(10.0 \%)\end{array}$ & $\begin{array}{l}\text { Barrientos-G. 2017, Basu } 2014 \text { a, Basu 2014b, } \\
\text { Ma } 2016\end{array}$ & $\begin{array}{l}{[41,42,44,} \\
60]\end{array}$ \\
\hline $\begin{array}{l}\text { Grupo } \\
5\end{array}$ & $\begin{array}{l}\text { Other, such as } \\
\text { cavities, } \rightarrow \\
\text { costs }\end{array}$ & $\begin{array}{l}1 \\
(2.5 \%)\end{array}$ & Schwendicke 2016 & [72] \\
\hline $\begin{array}{l}\text { Group } \\
6\end{array}$ & $\begin{array}{l}\text { Other } \rightarrow \text { any } \\
\text { other }\end{array}$ & $\begin{array}{l}1 \\
(2.5 \%)\end{array}$ & Lieffers 2018 & [58] \\
\hline
\end{tabular}

\section{Discussion}

Our systematic review offers a unique and up to date snapshot of current SSB models, and provides a detailed description of the 40 included studies regarding model features, inputs, results, pathways, interventions and applicability issues. This can significantly facilitate the use, adaptation or development of future models that improve current tools aiming to a successful SSB policy implementation.

It is noteworthy that less than half of the models were specifically designed to SSB, though all of them provided useful information in order to facilitate the use, adapt or develop a model in future endeavors. The information identified can beused in different contexts; we have included information from five continents, including some global approaches [25] and from all perspectives, including that of the healthcare system, government and the whole society.

Regarding the complexity of the required input parameters, most models need available or feasible inputs, like representative population surveys-mainly for obesity prevalence-, or vital statistics for mortality by conditions; though some other inputs -such as incidence or longitudinal data- could be more difficult to obtain in many settings but less models required them. This can also be true regarding the level of disaggregation of some parameters; for example, finding data by single year of ages or by gender could be difficult to get in some countries or regions. Information regarding SSB consumption could be 
difficult to find in Latin-American and Caribbean countries and specific information in children are usually unavailable. Additionally, the models that evaluate the impact of intervention required demand elasticity for SSB, ideally by age and gender groups, data not easily available in many countries.

The models offer relevant results to assess the burden of disease and / or the cost-effectiveness of interventions including the expected variation in SBB consumption of different policies,

obesity/overweight, diabetes, cardiovascular disease and mortality. Many of the models do not report results in a sufficiently disaggregated manner, thus limiting their applicability and usefulness to end users such as decision makers. SSBs consumption is really different among subgroups, in example adolescents usually consumes more than adults and there are big differences between gender by ages groups or quintiles of incomes.[78] Moreover, obesity and diseases prevalence also affect differently by gender, ages and income[9, 79, 80]; so is really usefully to have the opportunity to analyses the effects of SSB disaggregated.

Direct and indirect costs and quality of life-DALYs and QALYs- are measures that usually guide resource allocation and are valuable for decision makers; but only $57.5 \%$ and $40 \%$ of the models incorporated them respectively. Children were usually omitted in the majority of the studies, even being a widely affected population and a high priority target of prevention policies advocated by international organizations such as UNICEF and by numerous health systems.

It is encouraging that most of the interventions studied are the ones most grounded on evidence such as taxes, school food policies and advertising. [81, 82]

Our results show that a variety of SSB consumption specific modelling approaches have been used to understand its associated burden. Most of the published studies model the effects of SSB consumption trough increased $\mathrm{BMI}$ and the consequences in health -and sometimes in quality of life and cost- that implied. While sometimes the models separate the effects of diabetes, always is considered through BMI without include also the direct effect of SSB on diabetes.[83] Recently it was recognized a direct effect of SSB on cardiovascular disease (independently of BMI) that none model included.[84] The Australian Assessing Cost-Effectiveness (ACE) [85] was the most frequent used model, including adaptations to the USA $[50,52-54,56,59,66,70,74,77]$ This model is both time and data consuming and implies a great level of understanding of modelling issues for researchers and users, so it is probably difficult to apply to many countries. Our review finds many other model and model causal pathways that could be used.

A systematic review that evaluated the impact of a tax on SSB according to socio-economic status found that the models are focused on SSB consumption more than in health burden of disease; some models evaluate the impact on BMI but most of them only evaluated the impact on SSB consumption.[86] Similarly, to our findings, few studies specifically disaggregated results according to income groups.

Worldwide -and more in low- and middle-income countries- general population and decision-makers are not yet fully aware of the dimension of the problem that excessive SBB consumption is able to cause, so studies estimating the attributable disease burden are really important. Also, the interventions that need 
to be implemented -taxes, labeling, publicity limitation, environment school modifications- are politically and public sensitive and beverage industry frequently obstructs the implementation of them. [87] While SSB taxes have been implemented in over 40 countries and cities [88], the epidemiological shift towards NCDs diseases in low- and middle-income countries (LMICs) warrants even more a SSB control policy implementation of all the effective interventions available. [81, 82]

The value of non-communicable disease modelling to inform health policy is well established. [89-91] These models guide decisions of implementation of policies to improve risk factors for chronic diseases. Tobacco experience has shown that the burden of disease and economic evaluation have promoted the effective WHO framework implementation all around the world.[92] Four our focus related to SSB, we found 40 published models that attempt to assess this burden of disease information that could inform and promote the implementation of evidence-based policies aiming to decrease SSB consumption and its related burden. Implementing effective SSB policies is particularly important for LMICs with double nutritional burden of malnutrition and obesity.

With this information each country could select a simple or a more advanced model to apply in a particular country and also identify which are the main inputs and results that could be useful for taking decisions in the local context.

\section{Conclusions}

There is a wide range modelling approaches with different complexity and information requirements to evaluate the burden of disease attributable to SSB. The majority consider the impact on obesity, diabetes and cardiovascular disease, mortality, and economic impact. Incorporating these tools to different countries could generate useful information for decision makers and the general population to promote the deeper implementation of policies to diminish SSB consumption.

\section{Declarations}

\section{Ethics approval and consent to participate}

Not applicable.

\section{Consent for publication}

Not applicable

\section{Availability of data and materials}

The datasets used and/or analysed during the current study are available from the corresponding author on reasonable request.

\section{Competing interests}


The authors declare that they have no competing interests.

\section{Funding}

International Development Research Centre (IDRC) Project Number-Activity Number-Component Number: 108646-001. The sponsor supported all the activities and material needed to achieve the project objective, but it was not involved in any stage of the study.

\section{Authors' contributions}

AA coordinated the overall activities, designed the strategies, extracted data, plan the analysis, discussed the results and write the final draft. AC designed the strategies, extracted, plan and analyze data, discussed the results and write the final draft. APR, AP, AB y FA designed the strategies, extracted data, plan the analysis and discussed the results. DB and LP extracted data and discussed the results. All authors contributed to the interpretation of the results and contributed to edit the final draft.

\section{Acknowledgments}

Daniel Comandé, Mónica Soria, Natalie Soto, María Belén Rodriguez, Sebastian García Marti.

\section{References}

1. Murray CJ, Vos T, Lozano R, Naghavi M, Flaxman AD, Michaud C, Ezzati M, Shibuya K, Salomon JA, Abdalla $S$ et al. Disability-adjusted life years (DALYs) for 291 diseases and injuries in 21 regions, 1990-2010: a systematic analysis for the Global Burden of Disease Study 2010. Lancet 2012, 380(9859):2197-2223.

2. Beaglehole R, Bonita R, Horton R, Adams C, Alleyne G, Asaria P, Baugh V, Bekedam H, Billo N, Casswell S et al. Priority actions for the non-communicable disease crisis. Lancet 2011, 377(9775):1438-1447.

3. Sultan-Taieb H, Chastang JF, Mansouri M, Niedhammer I. The annual costs of cardiovascular diseases and mental disorders attributable to job strain in France. BMC Public Health 2013, 13:748.

4. Seuring T, Archangelidi O, Suhrcke M. The Economic Costs of Type 2 Diabetes: A Global Systematic Review. PharmacoEconomics 2015, 33(8):811-831.

5. Schmid T, Xu W, Gandra SR, Michailov G. Costs Of Treating Cardiovascular Events In Germany: A Systematic Literature Review. Value in health : the journal of the International Society for Pharmacoeconomics and Outcomes Research 2014, 17(7):A485.

6. Joo H, Zhang P, Wang G. Cost of informal care for patients with cardiovascular disease or diabetes: current evidence and research challenges. Quality of life research : an international journal of quality of life aspects of treatment, care and rehabilitation 2017, 26(6):1379-1386.

7. Gaziano TA. Economic burden and the cost-effectiveness of treatment of cardiovascular diseases in Africa. Heart (British Cardiac Society) 2008, 94(2):140-144. 
8. Evans N. Managing the cost of cardiovascular prevention in primary care. Heart (British Cardiac Society) 2004, 90 Suppl 4:iv26-28; discussion iv39-40.

9. Collaborators GBDO, Afshin A, Forouzanfar MH, Reitsma MB, Sur P, Estep K, Lee A, Marczak L, Mokdad AH, Moradi-Lakeh M et al. Health Effects of Overweight and Obesity in 195 Countries over 25 Years. N Engl J Med 2017, 377(1):13-27.

10. Ng M, Fleming T, Robinson M, Thomson B, Graetz N, Margono C, Mullany EC, Biryukov S, Abbafati C, Abera SF et al. Global, regional, and national prevalence of overweight and obesity in children and adults during 1980-2013: a systematic analysis for the Global Burden of Disease Study 2013. Lancet 2014, 384(9945):766-781.

11. Lozano R, Naghavi M, Foreman K, Lim S, Shibuya K, Aboyans V, Abraham J, Adair T, Aggarwal R, Ahn SY et al. Global and regional mortality from 235 causes of death for 20 age groups in 1990 and 2010: a systematic analysis for the Global Burden of Disease Study 2010. Lancet 2012, 380(9859):2095-2128.

12. Guh DP, Zhang W, Bansback N, Amarsi Z, Birmingham CL, Anis AH. The incidence of co-morbidities related to obesity and overweight: a systematic review and meta-analysis. BMC Public Health 2009, 9:88.

13. Malik VS, Pan A, Willett WC, Hu FB. Sugar-sweetened beverages and weight gain in children and adults: a systematic review and meta-analysis. The American journal of clinical nutrition 2013, 98(4):1084-1102.

14. Malik VS, Willett WC, Hu FB. Sugar-sweetened beverages and BMI in children and adolescents: reanalyses of a meta-analysis. The American journal of clinical nutrition 2009, 89(1):438-439; author reply $439-440$.

15. Vos MB, Kaar JL, Welsh JA, Van Horn LV, Feig DI, Anderson CAM, Patel MJ, Cruz Munos J, Krebs NF, Xanthakos SA et al. Added Sugars and Cardiovascular Disease Risk in Children: A Scientific Statement From the American Heart Association. Circulation 2017, 135(19):e1017-e1034.

16. Lauby-Secretan B, Scoccianti C, Loomis D, Grosse Y, Bianchini F, Straif K, International Agency for Research on Cancer Handbook Working G: Body Fatness and Cancer--Viewpoint of the IARC Working Group. N Engl J Med 2016, 375(8):794-798.

17. Jayalath VH, de Souza RJ, Ha V, Mirrahimi A, Blanco-Mejia S, Di Buono M, Jenkins AL, Leiter LA, Wolever TM, Beyene $\mathrm{J}$ et al. Sugar-sweetened beverage consumption and incident hypertension: a systematic review and meta-analysis of prospective cohorts. The American journal of clinical nutrition 2015, 102(4):914-921.

18. Mekonnen TA, Odden MC, Coxson PG, Guzman D, Lightwood J, Wang YC, Bibbins-Domingo K. Health benefits of reducing sugar-sweetened beverage intake in high risk populations of California: results from the cardiovascular disease (CVD) policy model. PloS one 2013, 8(12):e81723.

19. Wang H, Steffen LM, Zhou X, Harnack L, Luepker RV. Consistency between increasing trends in added-sugar intake and body mass index among adults: the Minnesota Heart Survey, 1980-1982 to 2007-2009. Am J Public Health 2013, 103(3):501-507. 
20. de Koning L, Malik VS, Kellogg MD, Rimm EB, Willett WC, Hu FB. Sweetened beverage consumption, incident coronary heart disease, and biomarkers of risk in men. Circulation 2012, 125(14):1735-1741, S1731.

21. Te Morenga L, Mallard S, Mann J. Dietary sugars and body weight: systematic review and metaanalyses of randomised controlled trials and cohort studies. Bmj 2012, 346:e7492.

22. Moynihan PJ, Kelly SA: Effect on caries of restricting sugars intake: systematic review to inform WHO guidelines. J Dent Res 2014, 93(1):8-18.

23. Rezende LF, Azeredo CM, Canella DS, Luiz Odo C, Levy RB, Eluf-Neto J. Coronary heart disease mortality, cardiovascular disease mortality and all-cause mortality attributable to dietary intake over 20years in Brazil. International journal of cardiology 2016, 217:64-68.

24. Meier T, Deumelandt P, Christen O, Stangl GI, Riedel K, Langer M. Global Burden of Sugar-Related Dental Diseases in 168 Countries and Corresponding Health Care Costs. J Dent Res 2017:22034517708315.

25. Vecino-Ortiz Al, Arroyo-Ariza D. A tax on sugar sweetened beverages in Colombia: Estimating the impact on overweight and obesity prevalence across socio economic levels. Social Science \& Medicine 2018, 209:111-116.

26. Singh GM, Micha R, Khatibzadeh S, Lim S, Ezzati M, Mozaffarian D. Estimated Global, Regional, and National Disease Burdens Related to Sugar-Sweetened Beverage Consumption in 2010. Circulation 2015, 132(8):639-666.

27. Lin BH, Smith TA, Lee JY, Hall KD: Measuring weight outcomes for obesity intervention strategies. The case of a sugar-sweetened beverage tax. Economics and Human Biology 2011, 9(4):329-341.

28. Huth PJ, Fulgoni VL, Keast DR, Park K, Auestad N. Major food sources of calories, added sugars, and saturated fat and their contribution to essential nutrient intakes in the U.S. diet: data from the National Health and Nutrition Examination Survey (2003-2006). Nutr J 2013, 12:116.

29. Pomeranz JL, Munsell CR, Harris JL. Energy drinks: an emerging public health hazard for youth. $J$ Public Health Policy 2013, 34(2):254-271.

30. Roberto CA, Swinburn B, Hawkes C, Huang TT, Costa SA, Ashe M, Zwicker L, Cawley JH, Brownell KD: Patchy progress on obesity prevention: emerging examples, entrenched barriers, and new thinking. Lancet 2015, 385(9985):2400-2409.

31. von Philipsborn P SJ, Burns J, Busert LK, Pfadenhauer LM, Polus S, Holzapfel C, Hauner H, Rehfuess E. Environmental interventions to reduce the consumption of sugar-sweetened beverages and their effects on health. Cochrane Database of Systematic Reviews 2016(7):CD012292.

32. Manyema M, Veerman JL, Chola L, Tugendhaft A, Labadarios D, Hofman K: Decreasing the Burden of Type 2 Diabetes in South Africa: The Impact of Taxing Sugar-Sweetened Beverages. PloS one 2015, 10(11):e0143050.

33. Cobiac LJ, Tam K. Taxes and Subsidies for Improving Diet and Population Health in Australia: A Cost-Effectiveness Modelling Study. 2017, 14(2):e1002232. 
34. Barrientos-Gutierrez T. Expected population weight and diabetes impact of the 1-peso-per-litre tax to sugar sweetened beverages in Mexico. PLoS medicine 2017, 12(5):e0176336.

35. Thomas R CKCealCJ, Papanicolas I, Smith PC, editors. Health system efficiency: How to make measurement matter for policy and management [Internet]. Copenhagen (Denmark): European Observatory on Health Systems and Policies; 2016. (Health Policy Series, No. 46.) 6. Available from: https://www.ncbi.nIm.nih.gov/books/NBK436886/.

36. Stroup DF, Berlin JA, Morton SC, Olkin I, Williamson GD, Rennie D, Moher D, Becker BJ, Sipe TA, Thacker SB. Meta-analysis of observational studies in epidemiology: a proposal for reporting. Metaanalysis Of Observational Studies in Epidemiology (MOOSE) group. JAMA 2000, 283(15):2008-2012.

37. Moher D, Liberati A, Tetzlaff J, Altman DG. Preferred reporting items for systematic reviews and meta-analyses: the PRISMA statement. PLoS Med 2009, 6(7):e1000097.

38. Babineau J. Product Review: Covidence (Systematic Review Software). Journal of the Canadian Health Libraries Association / Journal de l'Association des bibliothèques de la santé du Canada 2014, 35(2).

39. Covidence systematic review software. In. Melbourne, Australia: Veritas Health Innovation.

40. Brennan A, Chick SE, Davies R. A taxonomy of model structures for economic evaluation of health technologies. Health Econ. 2006 Dec;15(12):1295-310.

41. Afshin A, Micha R, Khatibzadeh S, Fahimi S, Shi P, Powles J, Singh G, Yakoob MY, Abdollahi M, AlHooti $S$ et al. The impact of dietary habits and metabolic risk factors on cardiovascular and diabetes mortality in countries of the Middle East and North Africa in 2010: A comparative risk assessment analysis. BMJ Open 2015, 5(5).

42. Barrientos-Gutierrez T, Zepeda-Tello R, Rodrigues ER, Colchero-Aragones A, Rojas-Martõnez R, Lazcano-Ponce E, Hernandez-Avila M, Rivera-Dommarco J, Meza R: Expected population weight and diabetes impact of the 1-peso-per-litre tax to sugar sweetened beverages in Mexico. PLoS ONE 2017, 12(5).

43. Basu S, Lewis K. Reducing Added Sugars in the Food Supply Through a Cap-and-Trade Approach. American Journal of Public Health 2014, 104(12):2432-2438.

44. Basu S, Seligman H, Bhattacharya J. Nutritional policy changes in the supplemental nutrition assistance program: a microsimulation and cost-effectiveness analysis. Medical Decision Making 2013, 33(7):937-948.

45. Basu S, Vellakkal S, Agrawal S, Stuckler D, Popkin B, Ebrahim S. Averting obesity and type 2 diabetes in India through sugar-sweetened beverage taxation: an economic-epidemiologic modeling study. PLoS Medicine 2014, 11(1):e1001582-e1001582.

46. Breeze PR, Thomas C, Squires H, Brennan A, Greaves C, Diggle P, Brunner E, Tabak A, Preston L, Chilcott J. Cost-effectiveness of population-based, community, workplace and individual policies for diabetes prevention in the UK. Diabetic Medicine 2017, 34(8):1136-1144.

47. Briggs AD, Mytton OT, Kehlbacher A, Tiffin R, Rayner M, Scarborough P. Overall and income specific effect on prevalence of overweight and obesity of $20 \%$ sugar sweetened drink tax in UK: econometric 
and comparative risk assessment modelling study. BMJ 2013, 347:f6189.

48. Briggs AD, Mytton OT, Madden D, O'Shea D, Rayner M, Scarborough P. The potential impact on obesity of a $10 \%$ tax on sugar-sweetened beverages in Ireland, an effect assessment modelling study. BMC public health 2013, 13:860.

49. Briggs ADM, Mytton OT, Kehlbacher A, Tiffin R, Elhussein A, Rayner M, Jebb SA, Blakely T, Scarborough P. Health impact assessment of the UK soft drinks industry levy: a comparative risk assessment modelling study. The Lancet Public Health 2017, 2(1):e15-e22.

50. Brown V, Ananthapavan J, Veerman L, Sacks G, Lal A, Peeters A, Backholer K, Moodie M. The Potential Cost-Effectiveness and Equity Impacts of Restricting Television Advertising of Unhealthy Food and Beverages to Australian Children. Nutrients 2018, 10(5):N.PAG-N.PAG.

51. Cobiac LJ, Tam K, Veerman L, Blakely T. Taxes and Subsidies for Improving Diet and Population Health in Australia: A Cost-Effectiveness Modelling Study. PLoS Medicine 2017, 14(2).

52. Collins B, Capewell S, O'Flaherty M, Timpson H, Razzaq A, Cheater S, Ireland R, Bromley H. Modelling the Health Impact of an English Sugary Drinks Duty at National and Local Levels. PLOS ONE [Electronic Resource] 2015, 10(6):e0130770.

53. Crino M, Mantilla Herrera AM, Ananthapavan J, Wu JHY, Neal B, Yong Yi L, Miaobing Z, Lal A, Sacks G. Modelled Cost-Effectiveness of a Package Size Cap and a Kilojoule Reduction Intervention to Reduce Energy Intake from Sugar-Sweetened Beverages in Australia. Nutrients 2017, 9(9):1-17.

54. Gortmaker SL, Long MW, Resch SC, Ward ZJ, Cradock AL, Barrett JL, Wright DR, Sonneville KR, Giles $\mathrm{CM}$, Carter RC et al. Cost Effectiveness of Childhood Obesity Interventions: Evidence and Methods for CHOICES. American Journal of Preventive Medicine 2015, 49(1):102-111.

55. Gortmaker SL, Wang YC, Long MW, Giles CM, Ward ZJ, Barrett JL, Kenney EL, Sonneville KR, Sadaf Afzal A, Resch SC et al. Three Interventions That Reduce Childhood Obesity Are Projected To Save More Than They Cost To Implement. Health Affairs 2015, 34(11):1932-1939.

56. Kristensen AH, Flottemesch TJ, Maciosek MV, Jenson J, Barclay G, Ashe M, Sanchez EJ, Story M, Teutsch SM, Brownson RC. Reducing childhood obesity through U.S. federal policy: a microsimulation analysis. American Journal of Preventive Medicine 2014, 47(5):604-612.

57. Lal A, Mantilla-Herrera AM, Veerman L, Backholer K, Sacks G, Moodie M, Siahpush M, Carter R, Peeters A. Modelled health benefits of a sugar-sweetened beverage tax across different socioeconomic groups in Australia: A cost-effectiveness and equity analysis. PLoS Medicine 2017, 14(6):1-17.

58. Lee BY, Ferguson MC, Hertenstein DL, Adam A, Zenkov E, Wang PI, Wong MS, Gittelsohn J, Mui Y, Brown ST. Simulating the Impact of Sugar-Sweetened Beverage Warning Labels in Three Cities. American Journal of Preventive Medicine 2018, 54(2):197-204.

59. Lieffers JRL, Ekwaru JP, Ohinmaa A, Veugelers PJ. The economic burden of not meeting food recommendations in Canada: The cost of doing nothing. PLOS ONE 2018, 13(4).

60. Long MW, Gortmaker SL, Ward ZJ, Resch SC, Moodie ML, Sacks G, Swinburn BA, Carter RC, Claire Wang Y. Cost Effectiveness of a Sugar-Sweetened Beverage Excise Tax in the U.S. American Journal 
of Preventive Medicine 2015, 49(1):112-123.

61. Ma Y, He FJ, Yin Y, Hashem KM, MacGregor GA. Gradual reduction of sugar in soft drinks without substitution as a strategy to reduce overweight, obesity, and type 2 diabetes. A modelling study. The Lancet Diabetes and Endocrinology 2016, 4(2):105-114.

62. Magnus A, Moodie ML, Ferguson M, Cobiac LJ, Liberato SC, Brimblecombe J. The economic feasibility of price discounts to improve diet in Australian Aboriginal remote communities. Australian \& New Zealand Journal of Public Health 2016, 40:S36-S41.

63. Manyema M, Veerman JL, Chola L, Tugendhaft A, Labadarios D, Hofman K. Decreasing the burden of type 2 diabetes in South Africa: The impact of taxing sugar-sweetened beverages. PLoS ONE 2015, 10(11).

64. Manyema M, Veerman LJ, Chola L, Tugendhaft A, Sartorius B, Labadarios D, Hofman KJ. The potential impact of a $20 \%$ tax on sugar-sweetened beverages on obesity in South African adults: A mathematical model. PLOS ONE 2014, 9(8).

65. Manyema M, Veerman LJ, Tugendhaft A, Labadarios D, Hofman KJ. Modelling the potential impact of a sugar-sweetened beverage tax on stroke mortality, costs and health-adjusted life years in South Africa. BMC Public Health 2016, 16(1):1-10.

66. Mekonnen TA, Odden MC, Coxson PG, Guzman D, Lightwood J, Wang YC, Bibbins-Domingo K. Health benefits of reducing sugar-sweetened beverage intake in high risk populations of California: Results from the Cardiovascular Disease (CVD) policy model. PLoS ONE 2013, 8(12).

67. Nomaguchi T, Cunich M, Zapata-Diomedi B, Veerman JL. The impact on productivity of a hypothetical tax on sugar-sweetened beverages. Health Policy 2017, 121(6):715-725.

68. Pearson-Stuttard J, Bandosz P, Rehm CD, Penalvo J, Whitsel L, Gaziano T, Conrad Z, Wilde P, Micha R, Lloyd-Williams F et al. Reducing us cardiovascular disease disparities through dietary policy. Circulation 2017, 135.

69. Penalvo JL, Cudhea F, Micha R, Rehm CD, Afshin A, Whitsel L, Wilde P, Gaziano T, Pearson-Stuttard J, O'Flaherty $\mathrm{M}$ et al. The potential impact of food taxes and subsidies on cardiovascular disease and diabetes burden and disparities in the United States. BMC Medicine 2017, 15(1):208.

70. Rezende LF, Azeredo CM, Canella DS, Luiz Odo C, Levy RB, Eluf-Neto J. Coronary heart disease mortality, cardiovascular disease mortality and all-cause mortality attributable to dietary intake over 20years in Brazil. International Journal of Cardiology 2016, 217:64-68.

71. Sacks G, Veerman JL, Moodie M, Swinburn B. Traffic-light nutrition labelling and junk-food tax: A modelled comparison of cost-effectiveness for obesity prevention. International Journal of Obesity 2011, 35(7):1001-1009.

72. Sanchez-Romero LM, Penko J, Coxson PG, Fernandez A, Mason A, Moran AE, Avila-Burgos L, Odden M, Barquera S, Bibbins-Domingo K. Projected Impact of Mexico's Sugar-Sweetened Beverage Tax Policy on Diabetes and Cardiovascular Disease: A Modeling Study. PLoS Medicine / Public Library of Science 2016, 13(11):e1002158. 
73. Schwendicke F, Thomson WM, Broadbent JM, Stolpe M. Effects of Taxing Sugar-Sweetened Beverages on Caries and Treatment Costs. Journal of Dental Research 2016, 95(12):1327-1332.

74. Singh GM, Micha R, Khatibzadeh S, Lim S, Ezzati M, Mozaffarian D: Estimated Global, Regional, and National Disease Burdens Related to Sugar-Sweetened Beverage Consumption in 2010. Circulation 2015, 132(8):639-666.

75. Veerman JL, Sacks G, Antonopoulos N, Martin J. The impact of a tax on sugar-sweetened beverages on health and health care costs: A modelling study. PLOS ONE 2016, 11(4).

76. Wang YC, Coxson P, Shen Y-M, Goldman L, Bibbins-Domingo K. A Penny-Per-Ounce Tax On SugarSweetened Beverages Would Cut Health And Cost Burdens Of Diabetes. Health Affairs 2012, 31(1):199-207.

77. Wilson KJ, Brown HS, Bastida E. Cost-effectiveness of a community-based weight control intervention targeting a low-socioeconomic-status Mexican-origin population. Health promotion practice $2015,16(1): 101-108$.

78. Wright DR, Kenney EL, Giles CM, Long MW, Ward ZJ, Resch SC, Moodie ML, Carter RC, Wang YC, Sacks $\mathrm{G}$ et al. Modeling the Cost Effectiveness of Child Care Policy Changes in the U.S. American Journal of Preventive Medicine 2015, 49(1):135-147.

79. Malik VS, Schulze MB, Hu FB. Intake of sugar-sweetened beverages and weight gain: a systematic review. The American journal of clinical nutrition 2006, 84(2):274-288.

80. Muennig P, Lubetkin E, Jia H, Franks P. Gender and the burden of disease attributable to obesity. Am $J$ Public Health 2006, 96(9):1662-1668.

81. Jiwani SS, Carrillo-Larco RM, Hernandez-Vasquez A, Barrientos-Gutierrez T, Basto-Abreu A, Gutierrez L, Irazola V, Nieto-Martinez R, Nunes BP, Parra DC et al. The shift of obesity burden by socioeconomic status between 1998 and 2017 in Latin America and the Caribbean: a cross-sectional series study. Lancet Glob Health 2019, 7(12):e1644-e1654.

82. Heise TL, Katikireddi SV, Pega F, Gartlehner G, Fenton C, Griebler U, Sommer I, Pfinder M, Lhachimi SK: Taxation of sugar-sweetened beverages for reducing their consumption and preventing obesity or other adverse health outcomes. Cochrane Database of Systematic Reviews 2016(8).

83. von Philipsborn P, Stratil JM, Burns J, Busert LK, Pfadenhauer LM, Polus S, Holzapfel C, Hauner H, Rehfuess E: Environmental interventions to reduce the consumption of sugar-sweetened beverages and their effects on health. Cochrane Database Syst Rev 2019, 6:CD 012292.

84. Malik VS, Popkin BM, Bray GA, Despres JP, Willett WC, Hu FB. Sugar-sweetened beverages and risk of metabolic syndrome and type 2 diabetes: a meta-analysis. Diabetes Care 2010, 33(11):2477-2483.

85. Yin J, Zhu Y, Malik V, Li X, Peng X, Zhang FF, Shan Z, Liu L. Intake of Sugar-Sweetened and LowCalorie Sweetened Beverages and Risk of Cardiovascular Disease: A Meta-Analysis and Systematic Review. Advances in Nutrition 2020.

86. Carter R, Moodie M, Markwick A, Magnus A, Vos T, Swinburn B, Haby MM. Assessing costeffectiveness in obesity (ACE-obesity): an overview of the ACE approach, economic methods and cost results. BMC Public Health 2009, 9:419.

Page 21/24 
87. Backholer K, Sarink D, Beauchamp A, Keating C, Loh V, Ball K, Martin J, Peeters A. The impact of a tax on sugar-sweetened beverages according to socio-economic position: a systematic review of the evidence. Public Health Nutr 2016, 19(17):3070-3084.

88. Du M, Tugendhaft A, Erzse A, Hofman KJ. Sugar-Sweetened Beverage Taxes: Industry Response and Tactics. Yale J Biol Med 2018, 91(2):185-190.

89. Bridge G, Lomazzi M, Bedi R. Implementation of a sugar-sweetened beverage tax in low- and middleincome countries: recommendations for policymakers. J Public Health Policy 2020, 41(1):84-97.

90. Stanaway JD, Afshin A, Gakidou E, Lim SS, Abate D, Abate KH, Abbafati C, Abbasi N, Abbastabar H, Abd-Allah $\mathrm{F}$ et al. Global, regional, and national comparative risk assessment of 84 behavioural, environmental and occupational, and metabolic risks or clusters of risks for 195 countries and territories, 1990\&\#x2013;2017: a systematic analysis for the Global Burden of Disease Study 2017. The Lancet 2018, 392(10159):1923-1994.

91. Webber L, Mytton OT, Briggs ADM, Woodcock J, Scarborough P, McPherson K, Capewell S. The Brighton declaration: the value of non-communicable disease modelling in population health sciences. European Journal of Epidemiology 2014, 29(12):867-870.

92. Lopez AD MC, Ezzati M, et al., editors. Washington (DC). The International Bank for Reconstruction and Development / The World Bank; New York: Oxford University Press; 2006.

93. Tobacco Free Initiative (TFI). Implementing tobacco control [https://www.who.int/tobacco/control/en/]

\section{Figures}



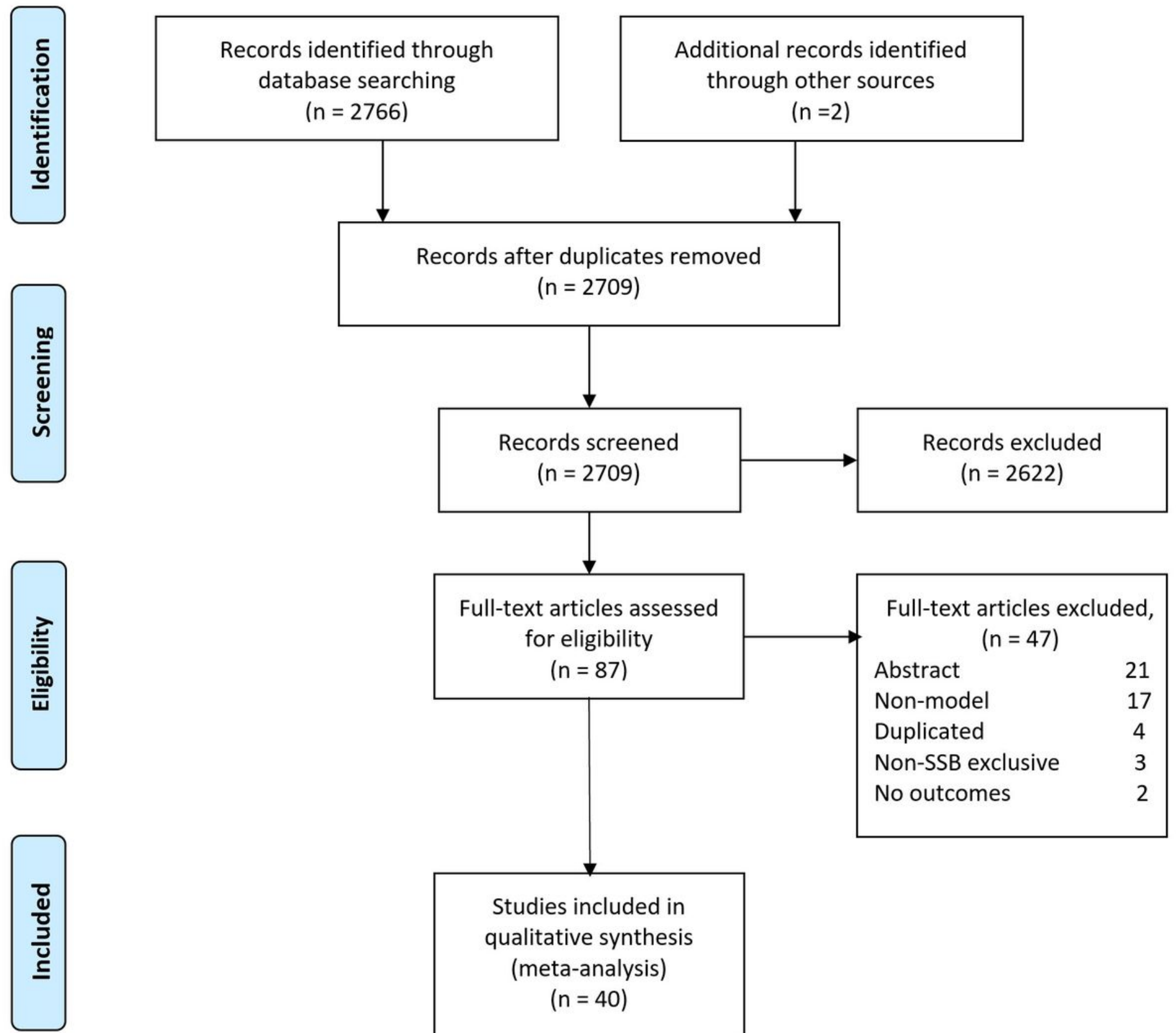

Studies included in qualitative synthesis

(meta-analysis)

$(n=40)$

Figure 1

Flow of studies in the systematic review 


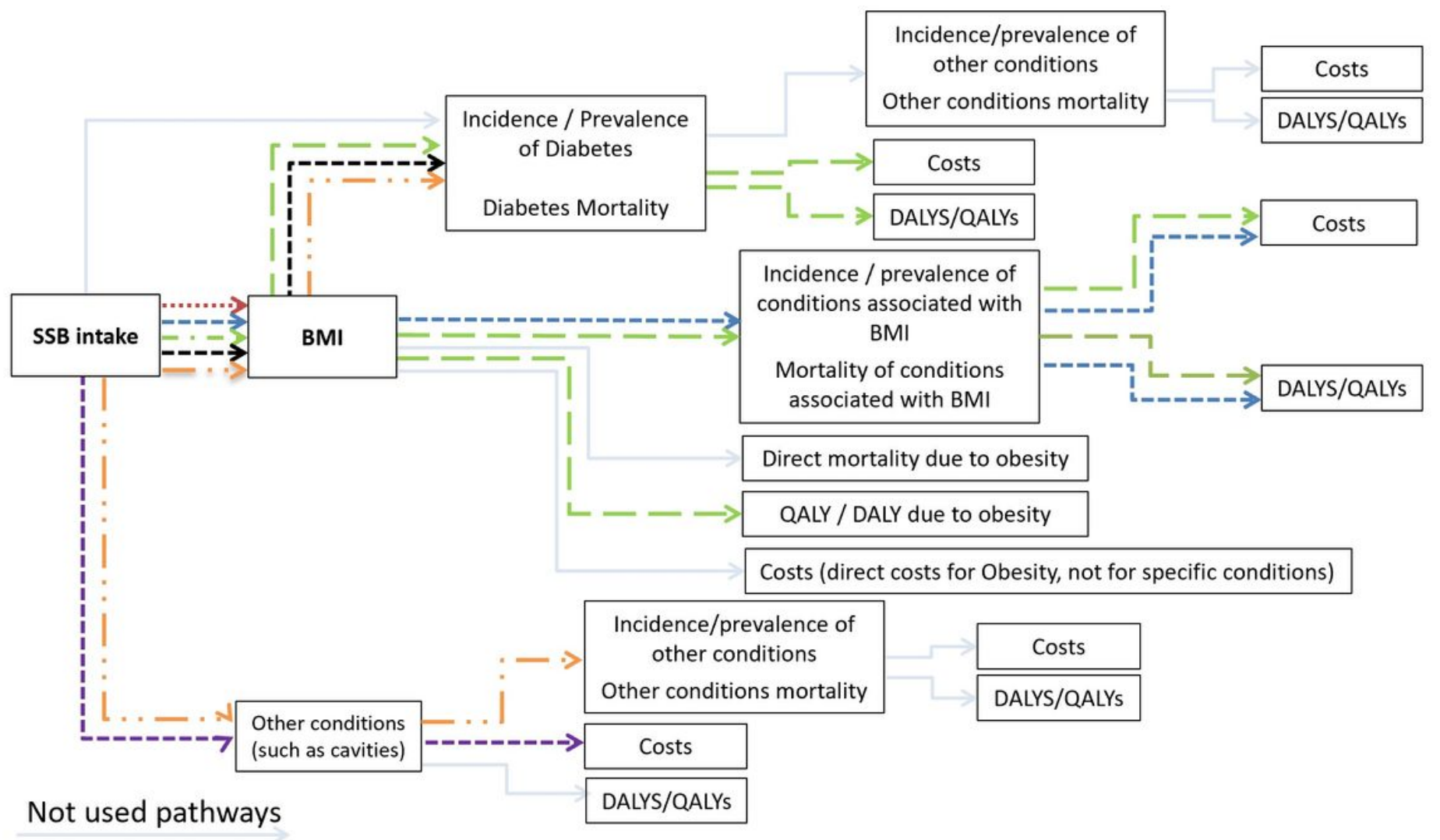

Group 4: BMI $\rightarrow$ Diabetes

Group 5: Other conditions (i.e.: cavities) $\rightarrow$ costs Group 6: Other conditions $\rightarrow$ any other

\section{Figure 2}

Models' pathways groups

\section{Supplementary Files}

This is a list of supplementary files associated with this preprint. Click to download.

- Additionalfile1to7.docx

- Additionalfile8Pathwaysbystudy.pdf 